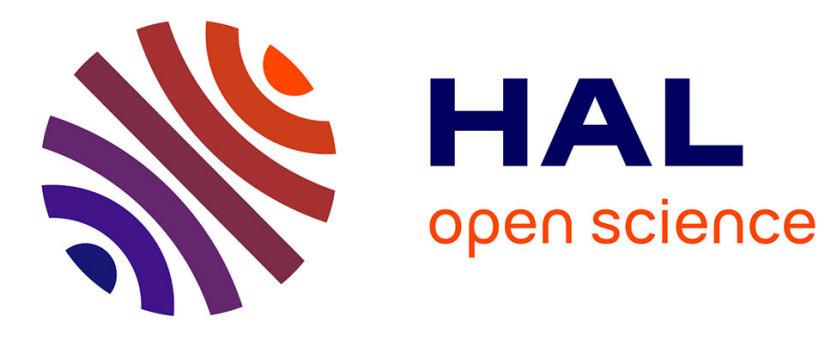

\title{
Financing and advising with (over)confident entrepreneurs: an experimental investigation
}

Laurent Vilanova, Nadège Marchand, Walid Hichri

\section{To cite this version:}

Laurent Vilanova, Nadège Marchand, Walid Hichri. Financing and advising with (over)confident entrepreneurs: an experimental investigation. 2015. halshs-01154514

\author{
HAL Id: halshs-01154514 \\ https://shs.hal.science/halshs-01154514 \\ Preprint submitted on 22 May 2015
}

HAL is a multi-disciplinary open access archive for the deposit and dissemination of scientific research documents, whether they are published or not. The documents may come from teaching and research institutions in France or abroad, or from public or private research centers.
L'archive ouverte pluridisciplinaire HAL, est destinée au dépôt et à la diffusion de documents scientifiques de niveau recherche, publiés ou non, émanant des établissements d'enseignement et de recherche français ou étrangers, des laboratoires publics ou privés. 
UMR 5824

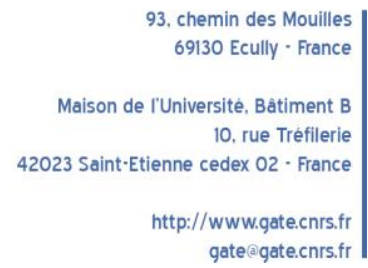

WP 1513 - May 2015

\title{
Financing and advising with (over)confident entrepreneurs: an experimental investigation
} Laurent Vilanova, Nadège Marchand, Walid Hichri

\begin{abstract}
:
We test in the laboratory how entrepreneurs' skill perceptions influence the design of financing and advising contracts. Our theoretical framework proposes that selfconfident entrepreneurs prefer issuing debt whereas low self-confident ones prefer equity which induces strong investor assistance. The prevalence of overconfidence makes investors more reluctant to accept debt offers and constrains self-confident entrepreneurs to finance through mixed securities. Experimental results show that self-confident entrepreneurs issue more debt-like securities and receive less assistance. We also show that entrepreneurs learn not to offer pure debt and that initial ignorance of their own skills reinforces entrepreneurs' ability to learn through risky choices.
\end{abstract}

Keywords:

Entrepreneurs, investment decision, learning, overconfidence, venture capital JEL codes:

C72, C92, D83

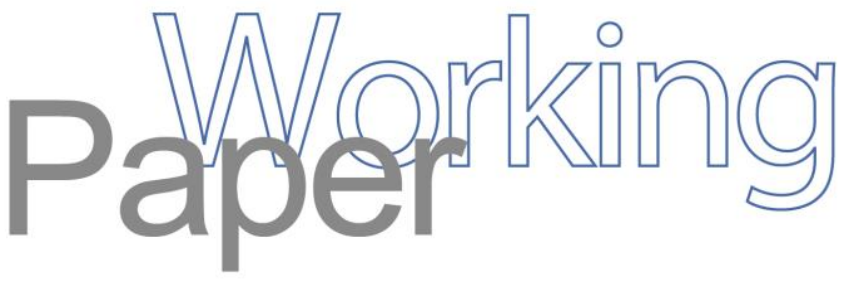




\section{Financing and advising with (over)confident}

\section{entrepreneurs: an experimental}

\section{investigation}

Laurent Vilanova $^{1}$, Nadège Marchand ${ }^{2}$ and Walid Hichri ${ }^{3}$

May 21, 2015

${ }^{1}$ Université Lyon 2, Coactis, E-mail: laurent.vilanova@univ-lyon2.fr

${ }^{2}$ Université de Lyon, Lyon, F-69007, France ; CNRS, GATE Lyon Saint-Etienne, Ecully, F-69130, France; Université Lyon 2, Lyon, F-69007, France. E-mail: nadege.marchand@gate.cnrs.fr

${ }^{3}$ Université de Lyon, Lyon, F-69007, France ; CNRS, GATE Lyon Saint-Etienne, Ecully, F-69130, France; Université Lyon 2, Lyon, F-69007, France. E-mail: walid.hichri@gate.cnrs.fr 


\begin{abstract}
We test in the laboratory how entrepreneurs' skill perceptions influence the design of financing and advising contracts. Our theoretical framework proposes that selfconfident entrepreneurs prefer issuing debt whereas low self-confident ones prefer equity which induces strong investor assistance. The prevalence of overconfidence makes investors more reluctant to accept debt offers and constrains self-confident entrepreneurs to finance through mixed securities. Experimental results show that self-confident entrepreneurs issue more debt-like securities and receive less assistance. We also show that entrepreneurs learn not to offer pure debt and that initial ignorance of their own skills reinforces entrepreneurs' ability to learn through risky choices.
\end{abstract}

JEL: C72, C92, D83.

Keywords : Entrepreneurs, investment decision, learning, overconfidence, venture capital. 


\section{Introduction}

In the face of high failure rates of new ventures and the low return of entrepreneurial activity (Moskowitz and Vissing-Jorgensen 2002), it is often argued that entrepreneurs exhibit too much confidence in their own abilities, in future outcomes and in their judgments (Busenitz 1999, Cooper et al. 1988, Palich and Bagby 1995). Whereas entrepreneurial overconfidence is viewed as the main reason of excess entry (Camerer and Lovallo 1999), little is known on the precise effect of overconfidence on some other key entrepreneurial decisions, such as the choice of start-up financing. The question is all the more important that the economics and finance literature suggests that financing choices significantly affect new ventures' performance. Accordingly, a common view is that venture capitalists provide valuable managerial inputs and increase the ex post performance of their portfolio firms (Kaplan and Strömberg 2004). Reconciling entrepreneurial overconfidence and the recurse to venture capital is however far from being obvious. For example, founders who overestimate their personal abilities may neglect resource needs of their venture and reject valuable social ties and/or external advice critical to success (Hayward et al. 2006). Following this idea, it is questionable whether overconfident entrepreneurs would be interested by the advising activity of venture capitalists.

The main objective of the paper is to test experimentally whether and how entrepreneurial self-confidence (possibly overconfidence) affects the choice of financing and advising contracts. Our game, inspired from the theoretical model of Vilanova (2013), considers the interaction between individuals that possess an investment project (henceforth, entrepreneurs) and investors. The probability of project success depends on the entrepreneur's skills, which depends within game on the entrepreneur's rank on a general quiz like in Camerer and Lovallo (1999). After the quiz, and without feedback on his quiz performance, each entrepreneur proposes a contract to the investor that specifies the repartition of outcomes in case of success and in case of failure. If the investor accepts the offer, the contract is signed and 
the investor sets the intensity of his advising activity (which is non contractible). This advising activity increases the project's probability of success in the sole case when the entrepreneur's performance to the quiz is low, i.e. when the entrepreneur is poorly skilled.

This simple framework permits to capture an entrepreneur's basic choice of financing, i.e., bank financing vs. venture capital financing (de Bettignies and Brander 2007, Winton and Yerramilli 2008). Banks' claims are poorly sensitive to the venture's performance and banks are often presented as passive investors that bring little advice to the firm. In contrast, venture capitalists are active investors that bring advising services to their portfolio firms. They also receive more "equity-like" securities that give them higher upside in case of sucess. According to Vilanova (2013), the trade-off between these two forms of financing should depend on the entrepreneur's skill perceptions. A high self-confident entrepreneur should naturally prefer to issue debt because (i) debt financing gives him a higher payoff in case of success, a state of nature that he considers as highly probable (ii) he believes that his own talent is sufficient to succeed and is, hence, reluctant to pay for a venture capitalist's advising activity. In contrast a low self-confident entrepreneur should prefer to issue an equity-like security that gives the investor more incentives to exert an advising effort. This suggests the existence of a natural separating equilibrium where high self-confident entrepreneurs issue debt securities and where low self-confident ones issue equity securities. The prevalence of entrepreneurial overconfidence - i.e. the fact that some high self-confident entrepreneurs overestimate their skills - could however affect the equilibrium contracting choices. Basically, if investors suspect entrepreneurial overconfidence, high self-confident entrepreneurs could be denied debt financing and could be obliged to issue securities that have more equity-features than their preferred choice. At the extreme, i.e. when overconfidence is highly pervasive, all the entrepreneurs (high- and low self-confident ones) could issue the same security and a pooling equilibrium might dominate. 
To our knowledge, our paper is the first to experimentally test how entrepreneurial (over)confidence affects equilibrium financing and advising contracts. Existing empirical studies (either in the laboratory or in the field) have focused on the behavioral consequences of overconfidence without considering the interactions with providers of resources. Along this line of inquiry, extent research has demonstrated that overconfident individuals are more likely to select risky projects and to overinvest (e.g. Camerer and Lovallo 1999, Malmendier and Tate 2008). Also highly-confident individuals tend to discount advice (Tost et al. 2012) and are less likely to seek for advice (See et al. 2011). Another stream of research has examined experimentally optimal contracting either in an adverse-selection context (Cabrales and Charness 2005) or in a principal-agent context (Anderhub et al. 2002). To our knowledge, however, there exists no empirical evidence on optimal contracting with potentially overconfident agents.

Our experiment also adresses the dynamics of contracting. Over time, entrepreneurs can revise their initial self-views, learn their true skills and adapt their contractual offers. During the first periods, entrepreneurs should set their offers according to their perceived skills and, because these perceptions might be upwardly biased, investors should apply an "overconfidence premium". In the final periods, entrepreneurs should be more informed about their true type and contractual offers should reflect their actual skills rather that their initial perceived skills. If learning takes place, final periods should give rise to a separating equilibrium where highskilled entrepreneurs and low-skilled entrepreneurs opt for debt securities and equity securities respectively. In our game, however, the convergence towards this separating equilibrium is not guaranteed. First, convergence could be hampered by the fact that entrepreneurs insufficiently adjust their beliefs to new information and/or by the fact that investors are doubtful about the entrepreneurs' capacity to learn their true skills. Second, consistent with the learning dynamics observed in the ultimatum game (Cooper et al. 1988, Slonim and Roth 1998), high-skilled entrepreneurs 
could learn not to offer securities that give investors a small fraction of outcomes, that is, pure debt securities. Hence, how optimal contracting evolves over time and experience is an open question that deserves further investigation.

The rest of the paper is the following. Section 2 presents the theoretical background. Section 3 adresses the experimental design. Section 4 presents the findings and we conclude in Section 5.

\section{Theoretical background}

We experimentally test a simplified version of the model proposed by Vilanova $(2013) .^{1}$

The model considers two players: F (the financier) and E (the entrepreneur). E needs 80 to finance a project but has no initial wealth. In order to finance his project, E must obtain funds from $\mathrm{F}$. We denote by $r$, the rate of return required by $\mathrm{F}$ in order to finance $\mathrm{E}$.

Project success depends on two parameters: E's managerial skills and the advising (or supporting) effort provided by F. E might possess high skills (type H) or low skills (type L). It is common knowledge that there is an equal proportion of type- $\mathrm{H}$ and of type-L in the economy. When $\mathrm{F}$ finances $\mathrm{E}$ but provides no advice $(M=0)$, the project managed by a type-H entrepreneur generates a final outcome 200 with probability 1 whereas the project managed by a type-L yields a final payoff 50 with probability 1 . The intensity of F's advising activity $(M)$ can however increase the chance of success of a venture managed by a type-L entrepreneur. We capture this value-adding effect of advising by considering that a project managed by a type-L entrepreneur is successful (yields 200) with probability $M$ and fails (yields 50) with probability $(1-M)$. Obviously, advising is costly and we denote by $c_{M}$ the cost of

\footnotetext{
${ }^{1}$ Vilanova (2013) proposes a double moral hazard model where the entrepreneur and the investor both exert effort after contracting and where both efforts affect the venture's final payoff. In this article, and in order to simplify the game for participants, we consider instead that only the investor's (advising) effort affects the venture's chance of sucess.
} 
advising effort for $\mathrm{F}$. We assume that this cost is an increasing and convex function in $M$.

The order of moves is the following:

1. Player $E$ offers a contract $C_{i}$ to player $F$. This contract specifies the allocation of cash flow rights depending on the project's final return. The contract proposes to pay $G_{i} \% 200$ to player $F$ in case of success and $P_{i} \% 50$ to player $F$ in case of failure. We restrict here the set of feasible contracts to four contracts (see Figure 1). These contracts can be distinguished on two dimensions: the equity component of the security offered to player F (or equivalently, the incentive package proposed to the financier) measured by $G_{i} \% 200-P_{i} \% 50$; the downside protection provided to the financier measured by $P_{i} \% 50$. We interpret payment schemes where financiers receive a low incentive package and a high downside protection as debt-like contracts. In contrast, contracts with a high incentive package and a low downside protection are interpretated as equity-like contracts. This leads us to interpret $C_{1}$ as an equity contract, $C_{2}$ as a debt contract, $C_{3}$ as a mixed security with a debt-like orientation and $C_{4}$ as a mixed security with an equity-like orientation.

\section{Insert Figure 1 about here}

2. Player $F$ accepts the offer or not. This decision depends on the offered contract, on player F's perceptions about player E's skills $\left(p_{H}^{F}\right)$ and on player F's required return $(r)$.

3. If the offer is accepted, the project is implemented and $F$ decides on the intensity of his advising activity $(M)$. The advising effort of player $F$ is not contractible. We use a mini-game" where we restrict the intensity of advising effort to four values, $M \in(0,0.25,0.5,0.75)$. Table 1 summarizes the four values of $M$ and their associated costs $c_{M}$. Notably, $c_{M}$ is an increasing and convex function in $M .^{2}$

\footnotetext{
${ }^{2}$ The values of $c_{M}$ in Table 2 were computed by assuming that $c_{M}=k M^{2} / 2$ with $k=160$ when $M=0.25$ and $k=150$ for $M=0.5$ and $M=0.75$.
} 


\section{Insert Table 1 about here}

Obviously, the choices made by $\mathrm{E}$ and $\mathrm{F}$ depend on their respective beliefs about the actual skills of the entrepreneur. We denote by $p_{H}^{E} \in[0,1]$, E's subjective belief that he is $\mathrm{H}$. The higher is $p_{H}^{E}$, the more $\mathrm{E}$ is self-confident. Symetrically, F will decide to accept the security offered by E and will choose the intensity of his advising activity according to $p_{H}^{F} \in[0,1]$, which denotes F's belief that $\mathrm{E}$ is of type $\mathrm{H}$.

In this setting, the contract $C_{i}$ offered by E should be the solution to the following maximization problem:

$$
\begin{gathered}
\underset{G_{i} \%, P_{i} \%}{M a x} p_{H}^{E}\left(1-G_{i} \%\right) 200+\left(1-p_{H}^{E}\right)\left[M\left(1-G_{i} \%\right) 200+(1-M)\left(1-P_{i} \%\right) 50\right] \\
M \in \arg \max \left\{p_{H}^{F} G_{i} \% 200+\left(1-p_{H}^{F}\right)\left[M G_{i} \% 200+(1-M) P_{i} \% 50\right]-c_{M}\right\} \\
p_{H}^{F} G_{i} \% 200+\left(1-p_{H}^{F}\right)\left[M G_{i} \% 200+(1-M) P_{i} \% 50\right]-c_{M}-(1+r) 80 \geq 0
\end{gathered}
$$

where (1) represents E's expected payoff, (2) is for F's IC constraint and (3) is for F's participation constraint.

As obvious here, there exist multiple solutions depending on the precise value of $p_{H}^{E}, p_{H}^{F}$ and $r$. A crucial point is that $p_{H}^{F}$ is partly contingent on the contract offer made by E. When setting his beliefs on E's skills, F accounts for the facts that (i) E's offer might convey information about E's self-confidence (i.e. $p_{H}^{E}$ ) and, (ii) even if E's offer perfectly reveals $p_{H}^{E}$, F might estimate that E's offer is an imperfect signal of E's true quality and might set $p_{H}^{F}<p_{H}^{E}$ if he suspects entrepreneurial overconfidence.

\subsection{Results of the static game}

In the static model presented above, where learning effects are absent, the main propositions are the following: 
Proposition 1 (F's advising effort): $F$ advising effort ( $M$ ) increases in the equity component of the offered contract, i.e. $\left(G_{i} \% 200-P_{i} \% 50\right)$, and decreases in F's perceptions of E's skills, i.e. $p_{H}^{F}$.

This is direct by computing the FOC of (2). The optimal advising effort of the player $\mathrm{F}$ is such that $c_{M}^{\prime}=\left(1-p_{H}^{F}\right)\left(G_{i} \% 200-P_{i} \% 50\right)$.

Proposition 2 (E's preferences): Highly-confident Es, i.e., those with high $p_{H}^{E}$, prefer to issue a security with a strong debt component ( $C_{2}$ optimally or $\left.C_{3}\right)$. In contrast, self-unconfident Es (i.e., those with low $p_{H}^{E}$ ) prefer to issue a security with a strong equity component ( $C_{1}$ optimally or $\left.C_{4}\right)$.

The intuition is straightforward. From (1), it is direct that an extremely selfconfident E (with $p_{H}^{E}=1$ ) believes that F's advising is useless. He is also prone to abandon all the project's cash flows in case of failure (i.e. to offer a contract with $\left.P_{i} \%=1\right)$. Then, he prefers to issue a security with a strong debt component that limits the intensity of investor advising effort. In contrast a low self-confident entrepreneur (i.e. a player $\mathrm{E}$ with low $p_{H}^{E}$ ) prefers intensive advising (high $\mathrm{M}$ ). Because F's advising effort cannot entirely compensate low entrepreneurial skills (i.e. $M<1$ ), he is also less prone to sacrify his payoff in case of failure than a high self-confident entrepreneur and prefers to set $P_{i} \%<1$. All in all, a low self-confident entrepreneur prefers to issue a security with a strong equity component.

\section{Proposition 3 (Separating equilibrium when players E have accurate} beliefs about their skills): When players Es beliefs are unbiased (presumably in final periods), that is when entrepreneurs accurately estimate their skill level:

- High self-confident/ High-skilled Es should offer a debt contract ( $\left.C_{2}\right)$, player $F$ should accept the offer and should set $M=0$.

- Low self-confident/ Low-skilled Es should issue equity $\left(C_{1}\right)$, player F should accept and should set $M=0.75$. 
If entrepreneurs have accurate self-beliefs, a separating equilibrium should arise. Consider the case of a player $\mathrm{E}$ of type $\mathrm{H}$. If accurate, this player should have beliefs $p_{H}^{E}=1$ and should offer a security with $P \%=1$. Observing this offer, F should induce that $\mathrm{E}$ is of type $\mathrm{H}\left(p_{H}^{F}=p_{H}^{E}=1\right)$ and should set his advising effort to $M=0$. Then, the optimal contract is such that $G_{i} \% 200=(1+r) 80$ and $P_{i} \% 50=50$, which resembles to contract $C_{2}$ in our "mini-game". Consider now the reverse case when the entrepreneur has low self-confidence and when both players share the same beliefs, i.e. $p_{H}^{F}=p_{H}^{E}=0$. In this case, both players agree on the necessity of a high advising effort. The low self-confident $\mathrm{E}$ has no incentive to mimick a high self-confident $\mathrm{E}$ by issuing $C_{2}$ because this would destroy player F's incentive to exert effort. He is then better off by issuing a security with a strong equity-component, which corresponds in our setting to $C_{1}$. When observing $C_{1}$, the financier should revise his beliefs to $p_{H}^{F}=0$ and should set his advising effort to $M=0.75 .^{3}$

\section{Proposition 4 (Optimal contracting when players E have available in-} formation but are suspected of being overconfident): When players E have available information about their skills but financiers suspect the presence of overconfident Es, players $F$ should reject debt offers $C_{2}$. High self-confident Es should rather issue mixed securities $\left(C_{3}\right.$ or $\left.C_{4}\right)$, financiers should accept and should exert an intermediate effort ( $M=0.25$ or 0.5$)$.

In our model, a suspicion of unrealistic optimism exists when $p_{H}^{F}<p_{H}^{E}$. Obviously this suspicion affects the choice of financing and advising contracts. Consider for instance the case of a high self-confident entrepreneur, $p_{H}^{E}=1$. By prediction 3 , we know that when entrepreneurs' beliefs are unbiased a high self-confident/high-skilled E prefers issuing a debt contract with $G \%=\frac{(1+r) I}{X^{g}}$ and $P \%=1$ that induces no advising effort $(M=0)$. This debt financing contract is accessible if the financier's

\footnotetext{
${ }^{3}$ If $\mathrm{E}$ offers $C_{1}$ and $p_{H}^{F}=0, c_{M}^{\prime}$ is equal to 150 , the highest possible value in our mini-game. Because $c_{M}$ is an increasing and convex function in $M, \mathrm{~F}$ will exert the highest possible effort, i.e. $M=0.75$.
} 
beliefs are similar to the ones of the entrepreneur $\left(p_{H}^{F}=p_{H}^{E}=1\right)$. In contrast, if player $\mathrm{F}$ suspects the presence of overconfident Es, i.e. if $p_{H}^{F}<p_{H}^{E} \equiv 1$, a high self-confident $\mathrm{E}$ has no other choice but to issue a security which provides a higher upside to the financier (with $G \% X^{g}>(1+r) I$ ) and that induces a strictly positive advising effort $(M>0)$. This contract that combines debt and equity components resembles more to a mixed security $\left(C_{3}\right.$ or $\left.C_{4}\right)$ than to pure debt. ${ }^{4}$

\section{Proposition 5 (Pooling equilibrium when players have no information}

on Es' skills): When players have no available information on entrepreneurial skills $\left(p_{H}^{F}=p_{H}^{E}=0.5\right)$, players E should issue a mixed security (either $C_{3}$ or $\left.C_{4}\right)$, players $F$ should accept and should set an intermediate advising effort ( $M=0.25$ or 0.5$)$.

In certain contexts, Es could have poor information about their skills. Within our game, this corresponds to a case where entrepreneurs have no private information about their entrepreneurial skills and set $p_{H}^{E}=0.5$, which corresponds to the proportion of type-H in the economy. In our model, this configuration precludes any (pooling) equilibrium with $C_{2}$ (because player's F participation constraint would not hold) or with $C_{1}$ (because player $\mathrm{E}$ is better off with a mixed security that offers a lower equity component to player $\mathrm{F}$ ).

\subsection{Learning and dynamic contracting}

A crucial point is that our theoretical framework does not adress how players' E beliefs evolve over time. When learning opportunities exist, that is, when players E can learn their true type through experience, the behavior of both players might differ from the ones described above. How contract offers and advising efforts evolve

\footnotetext{
${ }^{4}$ Formally speaking, whether Es with different self-confidence (those with high $p_{H}^{E}$ vs those with low $p_{H}^{E}$ ) separate or pool depends on the fraction of overconfident Es. If overconfidence is moderate, Es with high $p_{H}^{E}$ can still signal their high self-confidence by issuing a security with more debt features than the one issued by Es with low $p_{H}^{E}$ ). If, instead, overconfidence is high, all players $\mathrm{E}$ (those with high $p_{H}^{E}$ and those with low $p_{H}^{E}$ ) should issue the same mixed security (see Vilanova 2013). Also, in the latter case where a pooling equilibrium arises, the optimal contract (either $C_{3}$ or $C_{4}$ ) also depends on $r$, i.e. player's $\mathrm{F}$ required return.
} 
over time is however an open question.

If learning occurs, the base-line prediction is that players should converge towards the separating equilibrium described in Proposition 3. During the first periods, Es should set their offers according to their perceived skills and, because these perceptions might be upwardly biased, Fs should apply an overconfidence "premium". In particular, this suspicion of optimism could lead to systematic rejections of pure debt contracts $\left(C_{2}\right)$ in early rounds. In the final periods, players $\mathrm{E}$ should have updated their self-beliefs and should be more informed about their true type. Hence, contractual offers in late rounds should reflect their actual skills rather than their perceived skills and the separating equilibrium described in Proposition 3 should prevail.

Proposition 6 (Rational learning): Over time, players should converge towards the separating equilibrium described in Proposition 3 in which high-skilled Es offer pure debt securities (C2), low-skilled Es offer pure equity securities (C1) and where Fs accept to invest.

The speed of convergence towards this separating equilibrium obviously depends on players' capacity to implement strategies that reveal Es' true skills. In other terms, learning opportunities are not entirely exogeneous and partially depend on players' actions. In the multi-period version of the game, there exists a straightforward strategy for revealing the true skills of Es rapidly. This strategy consists, for Es, to propose a pure debt security in the first period $\left(C_{2}\right)$ and, for Fs, to accept this offer and to set $M=0$. If these strategies are implemented, observing the project outcomes at the end of the first period perfectly reveals Es' true skills, with success associated to a type-H entrepreneur and failure associated to a L-type entrepreneur. Afterwards, equilibrium contracting should be similar to the one arising when players E are perfectly accurate about their skills (see Prediction 3). In sum, entrepreneurs who are uncertain about their true skills could rapidly learn their skills by implementing a "learning through risky choice" strategy similar to the one 
described by Köszegi (2006).

Proposition 7 (Speed of convergence and learning through risky choice): When players are uncertain about Es' skills, there exists a strategy profile that permits to reveal Es' true skills at the end of the first period. This profile consists for Es to propose a pure debt security in the first period $\left(C_{2}\right)$ and, for Fs, to accept this offer and to set $M=0$. Such a strategy profile should accelerate convergence towards the separating equilibrium described in Proposition 3.

Laboratory evidence suggests, however, that players might not converge towards the separating equilibrium described in Proposition 3 after obtaining experience. Accordingly, experimental results in the ultimatum game typically show that "proposers" rarely make small offers, and that "responders" often reject small offers (Cooper et al. 2003, Slonim and Roth 1998). Because a pure debt security $\left(C_{2}\right)$ gives the financier a small fraction of project outcomes in success, these results suggest that, in our framework, pure debt offers might be made rarely, and might be frequently rejected when made. Explanations provided by reinforcement models of learning (Roth and Erev 1995) could apply here. In particular, the frequency with which high-skilled Es offer $C_{2}$ could diminish over time because of the high rejection rate of $C_{2}$ by Fs within first periods. Because of this high rejection rate, Es could offer less frequently $C_{2}$ in subsequent rounds even if type- $\mathrm{H}$ entrepreneurs might have learnt their type. In other words, high self-confident entrepreneurs (whether accurate or not) and high-skilled ones could learn not to offer pure debt securities. ${ }^{5}$

Proposition 8 (Reinforcement models of learning): Convergence towards the separating equilibrium described in Proposition 3 does not occur because high self-confident Es and/or type-H Es learn not to offer pured debt security $\left(C_{2}\right)$. The frequency of an offer $C_{2}$ should decrease over time and Fs should frequently reject this offer when made.

\footnotetext{
${ }^{5}$ An alternative reason for the non convergence towards the separating equilibrium where type$\mathrm{H}$ Es offer $C_{2}$ is that financiers could estimate that the profit sharing associated with this security is unfair (see for example Rabin 1993).
} 


\section{Experimental design}

The experiment is divided in four main treatments and each treatment is divided into two successive parts: a first part that aims to determine the skills of players E (either $\mathrm{H}$ or L-type) and to elicite skill perceptions; a second part where players E and $\mathrm{F}$ interact conformely to the financing and advising game described above.

The first part starts with a quiz composed of 10 questions dealing with general culture. After answering the questions, players are asked to evaluate their own relative performance. More precisely, participants are asked what probability they assign belonging to the above-median players (their relative performance). At the end of this first part, a computer program assigns a role ( $\mathrm{F}$ or $\mathrm{E}$ ) to each player to the session. Players E are classified according to their relative performance on the quiz (in skill rank treatments). A player $\mathrm{E}$ is classified as a H-type if he belongs to the $50 \%$ of players $\mathrm{E}$ that have the highest number of correct answers on the quiz and is classified as a L-type if he belongs to the $50 \%$ of players $\mathrm{E}$ that have the least correct answers on the quiz. Players are told whether they are F or E, but players

E don't know whether they are of type H or L. Obviously, each player E has his own belief (that could be true or false) about his ranking in the group and hence on his type. Notably, this belief relates to one's confidence in his relative abilities (Camerer and Lovallo 1999). In addition to the information concerning their role ( $\mathrm{F}$ or $\mathrm{E})$, we communicated to all players additional information on Es' beliefs at the group level in two of the five treatments. More precisely, we communicated the number of high self-confident Es and the number of type-H Es among those who expressed high self-confidence.

The second part of the experiment starts with a matching protocol where a computer program randomly matches a player E with a player F. We used a stranger design, wherein matching changes in the beginning of each period and a player never deals with the same individual during the experiment. After the matching is made, the game described in the preceding section begins. Sequentially: (1) Each player 
E offers a contract $C_{i}\left(\mathrm{G}_{i} \% .200, \mathrm{P}_{i} \% .50\right)$ to player $\mathrm{F}$; (2) each player $\mathrm{F}$ accepts the offer (and transfers 80 to player E) or rejects the offer (no transfer); (3) if the offer is accepted, F chooses his advising effort M. Table 2 summarizes the one-period payoff of each player. Participants were told their own payoff at the end of each period.

\section{Insert Table 2 about here}

Our experiment consists of five treatments with four tested parameters (see Table $3)$.

The first tested parameter is the rule used to rank Es, that is, the way Es are assigned to the type-H or type-L category. In treatments 1 to 3, Es are ranked according to their relative performance on the quiz (skill rank condition) and are classified as type $\mathrm{H}$ if they are above-median performers. In contrast, E's type is set according to a chance device in treatments 4 and 5 (random rank condition). If rational, each E should assign a 50\% probability for being a type-H in the randon rank condition. This distinction between skill-rank and random-rank conditions aims to capture whether inflated self-beliefs affect the equilibrium behavior of entrepreneurs and financiers. Indeed, we expect Es to be more self-confident and possibly more overconfident in the skill rank condition (Camerer and Lovallo 1999).

The second tested parameter concerns the additional information given to all players about self- and overconfidence on a group-level at the end of the first part of the experiment (after the quiz and before the choice of contracts). In treatment 2 , participants received no additional. In the treatments 1 and 3, players were informed on the percentage of highly self-confident Es and on the percentage of overconfident Es. Such an information should affect the securities $C_{i}$ offered by Es and the subsequent decisions of Fs (acceptation and advising effort). More specifically, we expect that the equilibrium described in Proposition 4 should be more likely when players receive information indicating that a substantial part of players E are overconfident. Indeed, in this case, Fs should be more reluctant to accept pure debt securities $\left(C_{2}\right)$ 
and highly self-confident Es should rather propose mixed securities. Note also that players did not receive additional information in random rank treatments (i.e. treatments 4 and 5) as participants should then rationally assign a 0.5 probability for a given $\mathrm{E}$ to be a type-H.

The third parameter tests the effect of the difficulty of the task in the skill rank condition. We used a difficult quiz in treatment 3 and an easy quiz in treatments 1 and 2. By manipulating quiz difficulty, we intended to generate variations in Es' self-confidence and overconfidence. This was motivated by the typical finding that individuals are more self-confident in their relative performance and are more likely to be overconfident in easy tasks rather than in difficult tasks (Hoelzl and Rustichini 2005, Moore and Healy 2008).

The last parameter is about the assignment of E's skills over periods. In the majority of our treatments, Es kept their type H or L unchanged over the 10 rounds of each session. In these treatments, learning opportunities existed and Es had the possibility to learn their true skills over time. This permits to test whether players converge (or not) towards the separating equilibrium described in Proposition 3, as discussed in Propositions 6 to 8. In treatment 5, Es potentially changed their type at each period as a new random affectation of type (type-H or type-L) was made at each round. This implies that Es had no opportunities to learn their true skills in treatment 5 . All in all, the conditions of treatment 5 are similar to those described in Proposition 5. Hence, in this treatment, we expected Es and Fs to implement the strategies described in Proposition 5 at each round. ${ }^{6}$

The following table summarizes the variation of the tested parameters in the different treatments:

\footnotetext{
${ }^{6}$ Importantly, the same individuals participated in treatments 4 and 5. More precisely, each participant played 20 rounds. During the first 10 periods (treatment 4), players E kept their type $\mathrm{H}$ or L over time. During the 10 subsequent periods (treatment 5 ), there was a new random affectation of type $\mathrm{H}$ or $\mathrm{L}$ to players $\mathrm{E}$ in each period. Hence, participants in treatment 5 were more experienced than those operating in other treatments. For the other treatments, participants played only 10 rounds.
} 


\section{Insert Table 3 about here}

The experiment was run in May 2010 at laboratory GATE in Lyon. Players were drawn from a database composed of more than 1600 persons. They were asked to participate to a computerized game. We used REGATE-NG as software and run four sessions. A number of 20 players participated to each session, which makes a total of 80 persons for the whole experiment. In the beginning of each session, players are affected randomly to each computer. They were asked not to communicate during all the experiment. Each session was composed of 10 periods and lasted about one hour, and players were paid in cash and in a private way at the end of the session according to a rate that converts points into euros according to the rate 1 euro for each 100 points.

\section{Findings}

\subsection{Skill perceptions}

We first analyse how participants evaluate their own performance after the quiz, i.e. at the end of the first part of the experiment.

As a preamble, we checked that the quiz used in treatment 3 is more difficult than the one used in the three other treatments. With the easy quiz, the average percentage of correct answers was $49 \%$ in Treatment 1, $54 \%$ in Treatment 2, and $53 \%$ in Treatment 4 . These values show a constant level of difficulty of the quiz for all groups in these "easy" treatments ( $52 \%$ of correct answers in average). In treatment 3 , the average percentage of correct answers was only $33,5 \%$ (cf. first line of Table 4). This confirms that the quiz used in treatment 3 is more difficult and can be used as a parameter to test the effect of the level of task difficulty.

Insert Table 4 about here 
The first measure of skill perceptions is participants' self-confidence, i.e. their perceptions of belonging to the above-median players (i.e. of being type $\mathrm{H}$ ). In our game a participant is self-confident when he sets a probability higher or equal to 0.5 of belonging to above-median players. Over all treatments, $62.5 \%$ of players E are highly self-confident (believe that they are H), which suggests overconfidence at the group level. Accordingly, Figure 2 shows that $27.5 \%$ of players E are overconfident (believe they are $\mathrm{H}$ although their true type is $\mathrm{L}$ ) after the quiz vs. $57.5 \%$ are realistic and $15 \%$ are underconfident (believe that they are L although they are $\mathrm{H}$ ).

Considering the effect of quiz difficulty on the skill perceptions of players E, Table 4 indicates that players $\mathrm{E}$ are more likely to be highly self-confident and overconfident in easy treatments (Treatments 1,2 and 4) than in difficult treatments (Treatment 3). This is consistent with findings in psychology which show that people tend to overestimate their relative performance in easy tasks (Moore and Healy 2008).

\section{Insert Figure 2 about here}

\subsection{Financiers' acceptation decision and advising effort}

The financier's decision to invest, i.e. to transfer funds, strongly depends on the contractual offers made by players E (Table 5). The propension of players F to invest is strictly increasing in the equity-like orientation of the offered security. At the two extremes, players $\mathrm{F}$ accept an offer $C_{2}$ (Debt) only $37.4 \%$ of the time and in contrast almost always accept an offer $C_{1}$ (Equity) (95.7\% of the time). Also, consistent with prediction 2, players F exert more advising effort with equityoriented securities than with debt-oriented securities. The average advising effort is 0.51 for contract $C_{1}$ (Equity) and of only 0.13 for contract $C_{2}$ (Debt). The advising effort of financiers is moderate with mixed securities, and as expected, is higher with contract $C_{4}$ (Mixed Equity) than with contract $C_{3}$ (Mixed Debt). 


\section{Insert Table 5 about here}

In analyzing the behavior of player $\mathrm{F}$, we face a sample selection bias as the dependant variable "M" (the intensity of advising effort) is observed only if player $\mathrm{F}$ has accepted the offer made by player E (Figure 3).

\section{Insert Figure 3 about here}

For a given F-player i, $y_{i 2}$ is not observed unless $y_{i 1}$ equals one. Therefore, the robustness of those observations is checked using a bivariate probit model with a sample selection bias that allows to estimate the probability of two simultaneous events, the acceptation and the advising decisions (Greene 1997). The results are given in Table 6.

In a first step, the decision to accept an offer is specified as a latent variable $y_{i 1}^{*}$, denoted:

$$
y_{i 1}=\left\{\begin{array}{c}
1 \text { if } y_{i 1}^{*}>0 \\
0 \text { otherwise }
\end{array}\right.
$$

It is assumed linear in the observables : $y_{i 1}^{*}=X_{i 1} \beta_{1}+u_{i 1}$ where $X_{i 1}$ includes two set of dummies. On the one hand, we capture our treatment effects through four dummies namely: treatments 1 to 5, except treatment 2 that is used as our benchmark. Treatment 5 corresponds to the last 10 periods of treatment 4 , where the type of $\mathrm{E}(\mathrm{H}$ or $\mathrm{L})$ is distributed randomly after each period. On the other hand, we set dummies for the contract offers $C_{1}, C_{2}$ and $C_{4}\left(C_{3}\right.$ is used as a benchmark).

In a second step, the decision to exert an advising effort conditional on the contract offer being accepted is specified as a latent variable, $y_{i 2}^{*}$, denoted:

$$
y_{i 2}=\left\{\begin{array}{c}
1 \text { if } y_{i 2}^{*}>0 \\
0 \text { otherwise }
\end{array}\right.
$$


We also assume that the latent variable is linear in the observables : $y_{i 2}^{*}=$ $X_{i 2} \beta_{2}+u_{i 2}$ where $X_{i 2}$ includes three variables, namely overconfidence treated as a dummy equal to 1 if player $\mathrm{E}$ is overconfident and 0 otherwise, and self-confidence which is set equal to 1 if player $\mathrm{E}$ is highly self-confident. The last variable captures the equity-orientation of the contract, and takes a value of 1 for contract $C_{2}$ (debt), 2 for $C_{3}$ (Mixed debt), 3 for $C_{4}$ (Mixed equity) and 4 for $C_{1}$ (Equity).

Finally, we use the Huber-White variance estimator to allow the fitting of our model that may contain heteroscedastic residuals because of the likely correlation between the observations associated to a same individual.

Table 6 reports the results of the two-steps probit regression.

\section{Insert Table 6 about here}

Results show that player F's decision to accept the offer, i.e., to invest, relies strongly on the type of contract offered by player E: $C_{1}$ (Equity) and $C_{4}$ (Mixed Equity) are more likely to be accepted than $C_{3}$ (Mixed Debt), whereas $C_{2}$ (Debt) is less likely to be accepted than $C_{3}$. Also, the financier propensity to exert an advising effort is increasing in the equity orientation of the security offered.

Acceptation decisions also differ according to treatments. For skill treatments (T1 to T3), players F are less likely to invest when they have feedback on the group level self-confidence and overconfidence of players E (Treatments 1 and 3 vs. Treatment 2). This could account for the fact that, in the absence of feedback indicating that players E have biased self-views, financiers suppose that players E are well calibrated (no self-deception). This is consistent with the "presumption of calibration" hypothesis advanced by Tenney et al. (2008) and Sah et al. (2013). In contrast, players $\mathrm{F}$ are more reluctant to invest when they receive explicit information that indicates the presence of miscalibrated Es. It is also noticeable that Fs are more reluctant to invest in Treatment 5 where ranking is random and changes every period, a context in which learning is impossible. 


\subsection{Entrepreneurs' contract offers}

Table 7 shows that players E frequently offer mixed securities. Contract $C_{1}$ (equity), the first best choice for low-skill Es, is rarely offered even if this contract is almost always accepted and generates the highest advising effort from player $\mathrm{F}$ (see Tables 5 and 6). The debt contract $\left(C_{2}\right)$ is more frequently offered than $C_{1}$ (equity) but is still less proposed than mixed securities $\left(C_{3}\right.$ and $\left.C_{4}\right)$, particularly in last rounds. Prima facie, the predominance of mixed securities could be explained by the suspicion of overconfidence. On the one side, some players E could be reluctant to offer the contract $C_{1}$ because they are overconfident and hence believe that the advising effort of $\mathrm{F}$ is unnecessary. Also, the fact that debt $\left(C_{2}\right)$ is less often proposed than mixed securities in last rounds could be due to the reluctance of financiers to accept a debt contract when they suspect the presence of overconfident entrepreneurs. This interpretation finds some support in the fact that the contract $C_{2}$ is often rejected by financiers (see Tables 5 and 6). Overall, mixed contracts dominate as predicted by the suspicion of overconfidence.

Our theoretical framework hypothesizes that the type of contracts proposed by entrepreneurs should depend both on their initial perceived skills (this effect should be more pronounced during the first rounds) and their actual skills. Table 7 illustrates the effect of actual skills and initial perceived skills on the offer of contracts (only for skill treatments T1, T2 and T3) and also illustrates the dynamics of contract choices by contrasting the first five periods ("first rounds") and the last five periods ("last rounds").

\section{Insert Table 7 about here}

Table 7 reveals that the proportion of pure debt offers $\left(C_{2}\right)$ is slightly higher for high- than for low self-confident entrepreneurs (31\% vs. 27\%). Partial support for Proposition 2, which predicts that high- and low self-confident should be more 
likely to issue pure debt and pure equity respectively during the first rounds of the experiment, is also provided by the fact that low self-confident Es proposed relatively more often pure equity $\left(C_{1}\right)$ during the first rounds $(17 \%$ of the offers vs. $9 \%$ for highly self-confident entrepreneurs). The learning effect, that stipulates that type-H entrepreneurs should converge towards debt-like securities $\left(C_{2}\right.$ and $\left.C_{3}\right)$ and type-L ones towards equity-like securities $\left(C_{1}\right.$ and $\left.C_{4}\right)$, finds some support in the results that $73 \%$ of high-skill Es opt for a debt-like security in the last periods of the experiment ( $37 \%$ choose $C_{2}$ and $36 \%$ choose $C_{3}$ ) and that $71 \%$ of low-skill Es opt for an equity-like security $\left(20 \%\right.$ choose $C_{1}$ and $51 \%$ choose $\left.C_{4}\right)$. However, the convergence occurs mainly through the issuance of mixed securities instead of pure securities, which departs from the "rational learning" hypothesis formulated in Proposition 6.

A possible interpretation for the absence of convergence towards "pure" contracts $C_{1}$ and $C_{2}$ across periods can be advanced. The fact that the frequency with which high-skill entrepreneurs offer $C_{2}$ (their first-best contract) diminishes across periods might be explained by the high rejection rate of $C_{2}$ by financiers during the first periods. In the subsequent rounds, players E offer less frequently the contract $C_{2}$ even if H-type entrepreneurs might have learnt their type throughout periods. This is obviously not consistent with rational learning, since we predicted in Proposition 6 that debt $\left(C_{2}\right)$ could be rejected in the first periods (when players $\mathrm{F}$ might presume overconfidence among players E) but should be more frequently accepted once entrepreneurs know precisely their skills (supposedly in the final periods). All in all, although entrepreneurs' skills seem to affects the choice of extreme contracts $\left(C_{1}\right.$ and $C_{2}$ ), the fact that both skilled and unskilled entrepreneurs converge towards offers of mixed securities across time suggests that our participants were unable to interpret the outcomes of the first periods to determine entrepreneurs' actual skills.

In order to evaluate the robustness of entrepreneurs' contract offers, we run a multinomial logistic regression. This allows us to investigate the relation between the 
contract's choice of players $\mathrm{E}$ and independent variables related to their individual characteristics (self-confidence, overconfidence, the time when their type is revealed) or structural variables such as rounds. In our game, a player E has to choose one of the four available contracts, the general form of the multinomial logit model can be written as:

$$
\operatorname{prob}(Y=j \mid X)=\frac{e^{X \beta_{j}}}{1+\sum e^{X \beta_{k}}} \text { for } \mathrm{j}=1,2,3,4
$$

The $\beta$ are the parameters of the model and $X$ is a vector of player characteristics. All specifications are normalized with respect to $C_{2}$. We also consider a variable quoted reveal_H that accounts for the fact that players $E$ have information that permits them to infer that they are of type H. ${ }^{7}$ Once informed, the dummy variable reveal_H is set to one.

\section{Insert Table 10 about here}

Results presented in Table 8 confirm that highly self-confident Es are less likely to offer pure equity than pure debt. The negative coefficients of the variable "Reveal_H" indicate that players E are less likely to offer securities with an equity component than pure debt when they have enough information to conclude that they are of type H. Overall, these results are consistent with the idea that Es with high-skill perceptions prefer to issue pure debt $\left(C_{2}\right)$ and provide support to Proposition 2. Although high-skill Es offer preferentially pure debt when they are in position to know their own skills, the positive coefficients of the variable "round" show, however, that players $\mathrm{E}$ tend to abandon contract $C_{2}$ over time in favor of other contracts, which suggests that reinforcement models of learning could apply here (see Proposition 8). Finally, it is noteworthy that E's overconfidence has no

\footnotetext{
${ }^{7}$ In our game, players $\mathrm{E}$ have this information when the following sequence of moves has been observed: player $\mathrm{E}$ has offered contract $C_{2}, \mathrm{~F}$ has accepted the offer and has set $M=0$, player $\mathrm{E}$ received 0 .
} 
effect on the contract offered. This may be due to the dual nature nature of overconfident Es who are jointly highly self-confident and low-skill. While their high self-confidence might lead them to offer pure debt during the first rounds, overconfident Es may have incentives to switch towards more equity-oriented securities (in particular to $C_{4}$ as suggested in Table 7 ) once they realize that they are low-skill.

Collectively, the results of our experiment suggest that high initial self-confidence increases the likelihood of pure debt contract offers during the first rounds. What happens in the following rounds depends on the reactions of players $\mathrm{F}$ to these initial offers. When these offers are rejected (which occurs frequently according to Table 5), highly self-confident Es cannot revise their self-beliefs and tend to switch towards mixed securities $C_{3}$ and $C_{4}$ in order to increase the likelihood of their offer being accepted. This is consistent with the idea that highly self-confident entrepreneurs learn not to offer pure debt securities (Proposition 8). If pure debt offers are accepted by players F during the first rounds, highly self-confident Es are more likely to learn their true type. Those who learn that they were realistic, i.e. type-H entrepreneurs, are more likely to persist in offering $C_{2}$ (cf. the negative coefficients of Reveal_H in Table 8). In contrast, those who discover that they were overconfident, i.e. type-L entrepreneurs, switch towards a more equity-oriented security $C_{4}$ (see Table 7 ).

\subsection{Differential payoffs across treatments and over time}

A final consideration is about the payoffs of participants. Figure 4 suggests that

high-skill Es gain more in T4, the treatment where their skills are initially set by a random device and are fixed across rounds. This is at first glance surprising because players E should be more able to evaluate their skills and should perform better in skill treatments (T1, T2, and T3). 


\section{Insert Figure 4 about here}

In order to validate this effect, we run a random effects GSL regression where the dependent variable is the average per-period payoffs of player $i$ (see Table 9). The regression is run on 80 individuals $(\mathrm{N}=80)$ observed during 10 periods. As illustrated in Table 9, player E earns significantly less than F, mainly because of the absence of endowment in the first stage of the game. Also, payoffs are higher when player $\mathrm{F}$ accepts the contract offered by $\mathrm{E}$ and when player $\mathrm{E}$ has high skills (Htype). Another important finding is that treatments have no impact on participants' payoffs, except for type-H entrepreneurs who have significantly higher payoffs in treatment 4 than in other treatments.

\section{Insert Table 9 about here}

Notably, the higher payoffs of type-H entrepreneurs in the random skill treatment 4 , whereby player $\mathrm{E}$ is more likely to offer a debt contract $C_{2}$ and player $\mathrm{F}$ is more likely to accept this offer than in skill treatments (see Table 5), seem consistent with the "learning through risky choice" strategy described in proposition 7 (Köszegi 2006). In other words, players E may have implemented in this treatment a deliberate research strategy, which consists in playing $C_{2}$ in the first rounds in order to discover their type. Indeed, in a dynamic setting, playing $C_{2}$ initially induces little advising effort from player $\mathrm{F}$ and permits to conclude very quickly if player $\mathrm{E}$ is $\mathrm{H}$ or L. One might wonder, however, why players did not implement such a profitable strategy in skill treatments. We leave this discussion for the next section.

\section{Discussion and conclusion}


Our objective was to test experimentally optimal contracting and advising when entrepreneurs are potentially overconfident.

The findings presented in the above section validate several of our theoretical predictions derived from Vilanova (2013). First, it appears that investors (players F) are more likely to finance entrepreneurs (players E) and are more likely to provide advising when they hold equity-oriented securities. Also, highly self-confident entrepreneurs - who believe that they are sufficiently skilled to succeed without external advice - are more likely to finance through debt-oriented securities, whereas those with low self-confidence finance preferentially their venture with equity-oriented securities. Consistent with our prediction that entrepreneurs' biased self-views might impede signaling, we also found that separation between high-skilled entrepreneurs and low-skilled ones did not prevail and that at equilibrium a significant fraction of entrepreneurs issue mixed securities. Interestingly, this experimental results fits well with the observation that venture capital investors often hold securities that combine equity and debt features (Kaplan and Strömberg 2003, 2004).

Our experiment also produces some interesting findings about the dynamics of optimal contracting. Surprisingly, we find very weak evidence of learning over time. Some reasons might be advanced. Notably, it appears that debt contracts were more frequently offered by entrepreneurs during the first rounds than in the last rounds of the experiment. This stands in direct contradiction with the base-line prediction that high-skill entrepreneurs should learn their true type over time and should converge towards debt financing in the last rounds of the game. A possible reason why highlyskill entrepreneurs do not converge towards debt financing is that financiers tend to largely reject debt offers in the first rounds. While this rejection is natural in the first rounds (because financiers might suspect overconfidence among entrepreneurs), the paradox is that offers of debt contracts durably disappeared. In sum, we find that an equilibrium emerges where pure debt contract are definitively selected out even if rational learning suggests that experienced and high-skill entrepreneurs should 
converge towards this type of financing. Although not consistent with rational learning, this finding is concordant with the predictions of reinforcement models of learning (Cooper et al. 2003, Roth and Erev 1995, Slonim and Roth 1998). All occurs as if entrepreneurs learn not to offer pure debt, by inferring that early rejections of debt offers make highly probable that financiers will continue to reject debt in the future.

The finding that high-skill entrepreneurs obtain higher gains when they are initially more uncertain about their type (i.e., when their type is set according to a chance device rather than to their relative performance on the quiz) is also a priori striking. Notably, our experiment shows that subjects were more likely to implement a rational "learning through risky choice" strategy (that consists for the entrepreneur to offer debt, and for the financier to accept the offer and to provide a low advising effort) and, hence, entrepreneurs were more likely to learn their true type rapidly when entrepreneurs had less precise self-beliefs at the beginning of the game. A potential explanation of why this strategy was implemented less often in treatments where the entrepreneur's type was set according to his relative performance may be found in the literature on information avoidance. According to Köszegi (2006), agents derive ego utility from positive views about the self and don't want new information that may taint their positive self-image. In our experimental setting, the revelation of the entrepreneur's type is more likely to threaten self-image when type depends on (relative) skills rather than on a random device. ${ }^{8}$ Therefore, and consistent with our findings, entrepreneurs, particularly those who are highly confident in their abilities, should be more reluctant to take the risk of learning their true type and to implement a "learning through risky choice" strategy in skill rank condition than in random rank condition. While providing further support to the ego utility argument of Köszegi (2006) (see also Eil and Rao, 2011), this result also suggests an-

\footnotetext{
${ }^{8}$ In the skill rank condition, the revelation that he is a type- $\mathrm{L}$ signals to the entrepreneur that he is an above-median performer in the quiz. In contrast, such revelation only signals "bad luck" in the random rank condition.
} 
other channel through which entrepreneurs' highly confident self-beliefs might hurt the performance of new ventures. Not only, these beliefs may lead individuals to neglect the quality of their competitors (Camerer and Lovallo 1999), but also they may prevent them from learning their true abilities through experience. Accordingly, our findings suggest that initially ignorant entrepreneurs (presumable novice ones) may implement more effective strategies than experienced ones. In contrast, experienced entrepreneurs may develop rigid and possibly overconfident self-beliefs over time, a result consistent with the heuristics and biases research, which argues for an increased risk of overconfidence among experts (Yates et al. 1991). It is important to note, however, that in our two-players setting the absence of "ego utility" motive is not sufficient to explain the adoption of the "learning through risky choice strategy" in the random rank condition. To be effective, i.e., to reveal the entrepreneur's true type, a debt offer must be followed by a specific sequence of moves by the financier (acceptation of the offer and low advising effort). The fact that financiers were more likely to adopt this sequence of moves in random rank treatments may indicate that financiers anticipate that entrepreneurs are more prone to revise their self-beliefs and to learn their true type when ego utility is not at stake.

Obviously, this paper is only a first step to explain the dynamics of optimal contracting between potentially overconfident entrepreneurs and potentially advising investors. In particular, further work should try to disentangle the extent to which the dynamics of entrepreneurs' contract offers reflects the evolution of their selfbeliefs over time and/or their anticipation of investors' responses. 


\section{References}

Anderhub, V., S. Gächter, and M. Königstein (2002). Efficient contracting and fair play in a simple principal-agent experiment. Experimental Economics 5, 5-27.

Busenitz, L. W. (1999). Entrepreneurial risk and strategic decision making: It's a matter of perspective. Journal of Applied Behavioral Science 35 (3), 325-340.

Cabrales, A. and G. Charness (2005). Optimal contracts, adverse selection, and social preferences: An experiment. Working paper Universitat Pompeu Fabra.

Camerer, C. and D. Lovallo (1999). Overconfidence and excess entry: An experimental approach. American Economic Review 89, 306-318.

Cooper, A., C. Woo, and W. Dunkelberg (1988). Entrepreneurs' perceived chances for success. Journal of Business Venturing 3, 97-108.

Cooper, D. J., N. Feltovich, A. E. Roth, and R. Zwick (2003). Relative versus absolute speed of adjustment in strategic environments: responder behavior in ultimatum games. Experimental Economics 6, 181-207.

de Bettignies, J.-E. and J. Brander (2007). Financing entrepreneurship: Bank finance versus venture capital. Journal of Business Venturing 6, 808-832.

Eil, D. and J. M. Rao (2011). The good news-bad news effect: asymmetric processing of objective information about yourself. American Economic Journal: Microeconomics 3(2), 114-138.

Greene, W. H. (1997). Econometric analysis. 1997. Inglewood Cliffs.

Hayward, M., D. Shepherd, and D. Griffin (2006). A hubris theory of entrepreneurship. Management Science 52, 160-172.

Hoelzl, E. and A. Rustichini (2005). Overconfident: Do you put your money on it? The Economic Journal 115, 305-318. 
Kaplan, S. and P. Strömberg (2003). Financial contracting meets the real world: An empirical analysis of venture capital contracts. Review of Economic Studies 70, $281-315$

Kaplan, S. and P. Strömberg (2004). Characteristics, contracts, and actions: Evidence from venture capitalist analyses. Journal of Finance 59, 2177-2210.

Köszegi, B. (2006). Ego utility, overconfidence, and task choice. Journal of the European Economic Association 4, 673-707.

Malmendier, U. and G. Tate (2008). Who makes acquisitions? ceo overconfidence and the market's reaction. Journal of Financial Economics 89, 20 - 43.

Moore, D. and P. Healy (2008). The trouble with overconfidence. Psychological Review 115 (2), 502-517.

Moskowitz, T. and A. Vissing-Jorgensen (2002). The returns to entreprenurial investment: A private equity premium puzzle. American Economic Review 92 (4), $745-778$

Palich, L. E. and D. R. Bagby (1995). Using cognitive theory to explain entrepreneurial risk-taking: Challenging conventional wisdom. Journal of Business Venturing 10, $425-438$.

Rabin, M. (1993). Incorporating fairness into game theory and economics. The American economic review, 1281-1302.

Roth, A. E. and I. Erev (1995). Learning in extensive-form games: Experimental data and simple dynamic models in the intermediate term. Games and economic behavior 8, 164-212.

Sah, S., D. A. Moore, and R. J. MacCoun (2013). Cheap talk and credibility: The consequences of confidence and accuracy on advisor credibility and persuasiveness. Organizational Behavior and Human Decision Processes Forthcoming. 
See, K. E., E. W. Morrison, N. B. Rothman, and J. B. Soll (2011). The detrimental effects of power on confidence, advice taking, and accuracy. Organizational Behavior and Human Decision Processes 116, 272-285.

Slonim, R. and A. E. Roth (1998). Learning in high stakes ultimatum games: An experiment in the slovak republic. Econometrica, 569-596.

Tenney, E. R., B. A. Spellman, and R. J. MacCoun (2008). The benefits of knowing what you know (and what you don't): How calibration affects credibility. Journal of Experimental Social Psychology 44, 1368 - 1375.

Tost, L. P., F. Gino, and R. P. Larrick (2012). Power, competitiveness, and advice taking: Why the powerful don't listen. Organizational Behavior and Human Decision Processes 117, 53-65.

Vilanova, L. (2013). Financing and managerial support with (some) optimistic entrepreneurs. Working Paper University of Lyon.

Winton, A. and V. Yerramilli (2008). Entrepreneurial finance: Banks versus venture capital. Journal of Financial Economics 88, 51-79.

Yates, J. F., L. S. McDaniel, and E. S. Brown (1991). Probabilistic forecasts of stock prices and earnings: The hazards of nascent expertise. Organizational Behavior and Human Decision Processes 49, 60-79. 


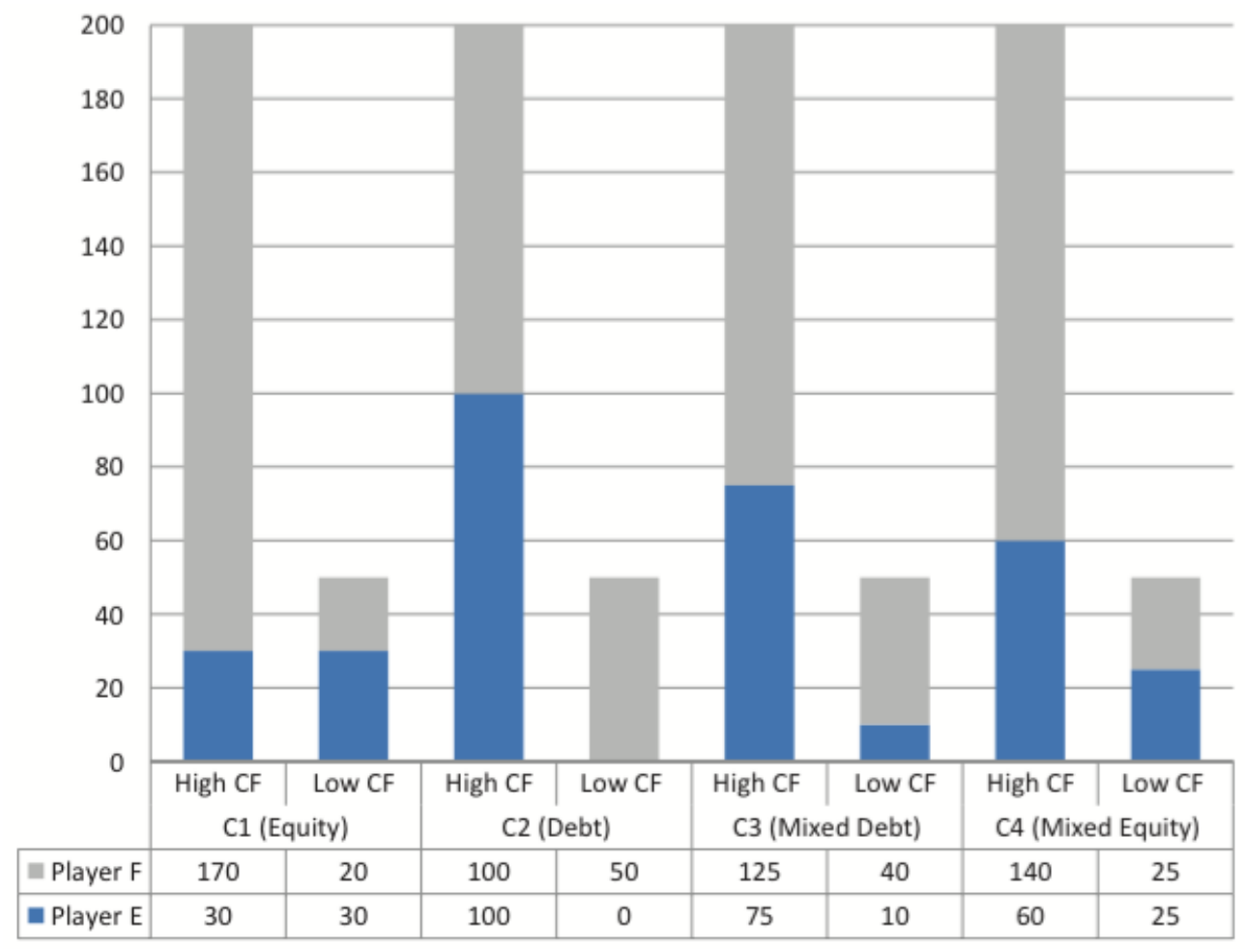

Figure 1: Contract offers and players' one-period contractual payoffs

"High CF" is for the case when the project's final cash flows are 200 and "Low CF" is for the case when the final cash flows are 50 .

\begin{tabular}{|l|l|l|l|l|}
\hline Value of $M$ & 0 & 0.25 & 0.5 & 0.75 \\
\hline Cost $c_{M}$ & 0 & 5 & 19 & 42 \\
\hline
\end{tabular}

Table 1: Intensity and cost of advising activity

\begin{tabular}{|c|c|c|c|}
\cline { 3 - 3 } \multicolumn{2}{c|}{} & \multicolumn{2}{c|}{ Player E } \\
\cline { 3 - 4 } \multicolumn{2}{c|}{} & Project's final cash flow $=200$ & Project's final cash flow $=50$ \\
\hline \multirow{2}{*}{ Player F } & Transfer 80 to player E & $G_{i} \% .200-c_{M} ;\left(1-G_{i}\right) \% .200$ & $P_{i} \% .50-c_{M} ;\left(1-P_{i}\right) \% .50$ \\
\cline { 2 - 4 } & No Transfer & \multicolumn{2}{|c|}{$80 ; 0$} \\
\hline
\end{tabular}

Table 2: Players' one-period payoffs 


\begin{tabular}{|l|c|c|c|c|c|}
\hline $\begin{array}{l}\text { Rank condition for players } \\
\text { E }\end{array}$ & Skill & Skill & Skill & Random & Random \\
\hline $\begin{array}{l}\text { Information about self- } \\
\text { and over- confidence at the } \\
\text { group level }\end{array}$ & Yes & No & Yes & No & No \\
\hline Difficulty of the quiz & Easy & Easy & Difficult & Easy & Easy \\
\hline $\begin{array}{l}\text { Assignment of E's skills } \\
\text { throughout periods }\end{array}$ & Fixed & Fixed & Fixed & Fixed & Random \\
\hline
\end{tabular}

Table 3: Tested parameters in the different treatments

\begin{tabular}{|c|c|c|}
\hline Treatments & Easy $(\mathrm{T} 1 / \mathrm{T} 2 / \mathrm{T} 4)$ & Difficult (T3) \\
\hline \% of correct answers & $52 \%$ & $33.5 \%$ \\
\hline \% of high self-confident Es & $70 \%^{* * *}$ & $40 \%^{* * *}$ \\
\hline \% of overconfident Es & $30 \%^{*}$ & $20 \%^{*}$ \\
\hline
\end{tabular}

Table 4: Effects of treatment difficulty on quiz performance and skill perceptions $(* * *)$ indicates that the difference is significant at the $1 \%$ level with the Pearson chi-square

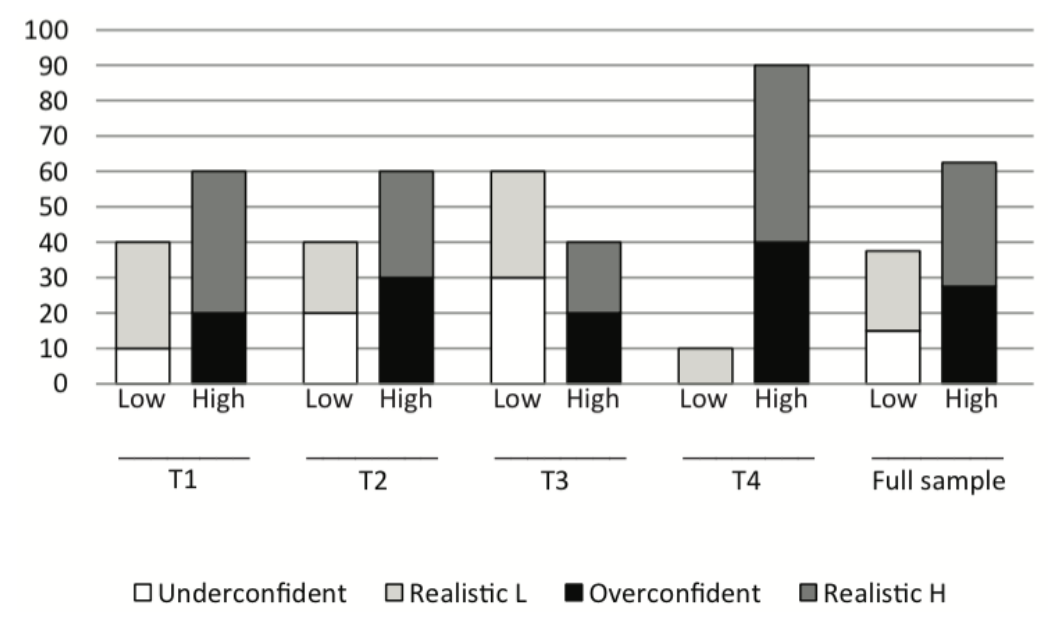

Figure 2: Skill (mis)perceptions of players E across treatments (in \%)

"Low" is for low self-confident and "High" is for high self-confident. Full sample includes all treatments except $\mathrm{T} 5$. 


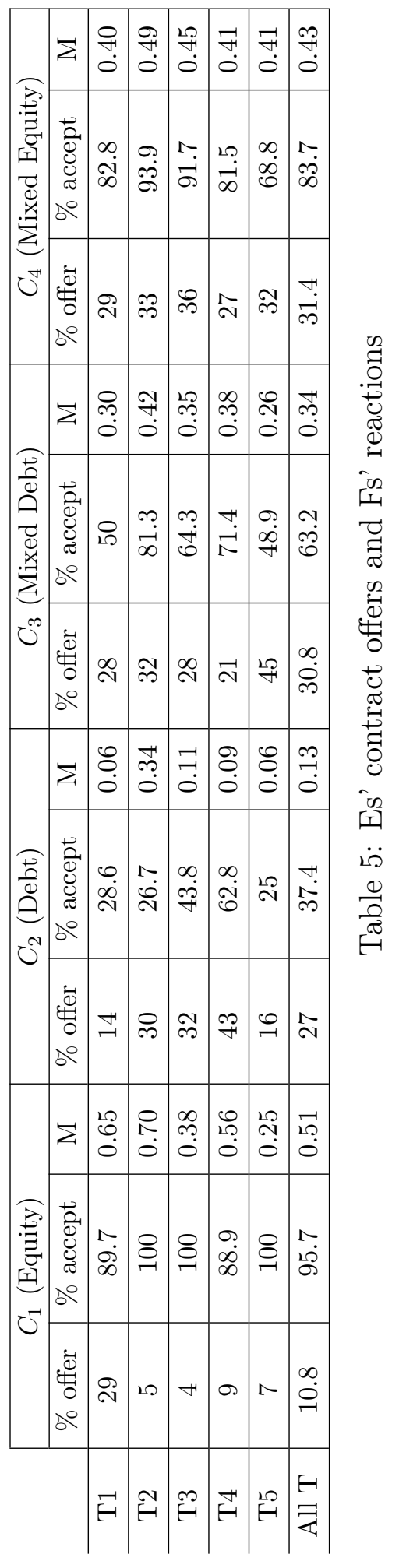




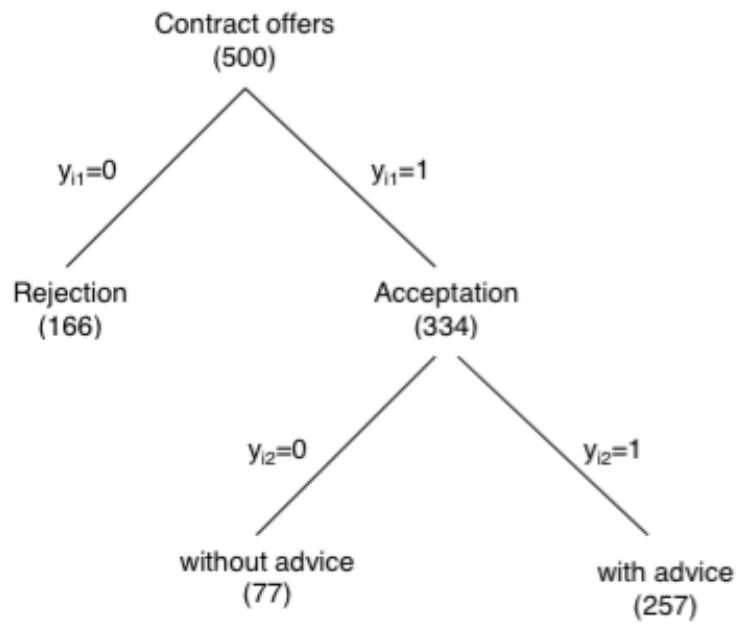

Figure 3: Observed values for $y_{i 1}$ and $y_{i 2}$ in the experiment

\begin{tabular}{lcc} 
Variable & Coefficient & (Std. Err.) \\
\hline Equation 1 : acceptation by F & \\
\hline Treatment 1 & $-0.556^{* * *}$ & $(0,200)$ \\
Treatment 3 & $-0,160$ & $(0,191)$ \\
Treatment 4 & $-0,001$ & $(0,200)$ \\
Treatment 5 & $-0.660^{* * *}$ & $(0,191)$ \\
C1 (Equity) & $1.188^{* * *}$ & $(0,280)$ \\
C2 (Debt) & $-0.726^{* * *}$ & $(0,167)$ \\
C4 (Mixed Equity) & $0.721^{* * *}$ & $(0,160)$ \\
Intercept & $0.641^{* * *}$ & $(0,162)$ \\
\hline Equation 2 : advising effort (M) provided by F & \multicolumn{2}{c}{$(0.094)$} \\
\hline Equity orientation & $0.361^{* * *}$ \\
Intercept & 0.176 \\
\hline N & \multicolumn{2}{c}{500} \\
\hline Log-likelihood & \multicolumn{2}{c}{-424.572} \\
$\chi^{2}()$. & \multicolumn{2}{c}{130.886} \\
& \multicolumn{2}{c}{.000}
\end{tabular}

Table 6: Financiers' reactions (acceptation decision and intensity of advising effort) to Es' offers

$(* * *)$ : Significant at the 0.01 level; $(* *)$ : significant at the 0.05 level; $(*)$ significant at the 0.1 level.

The dependent variables of equation 1 are dummy variables for treatments with treatment 2 set as the benchmark and the contract choices with Mixed-debt contract, $C_{3}$ as the benchmark. Please, refer to Table 3 for a full description of the four treatments. 


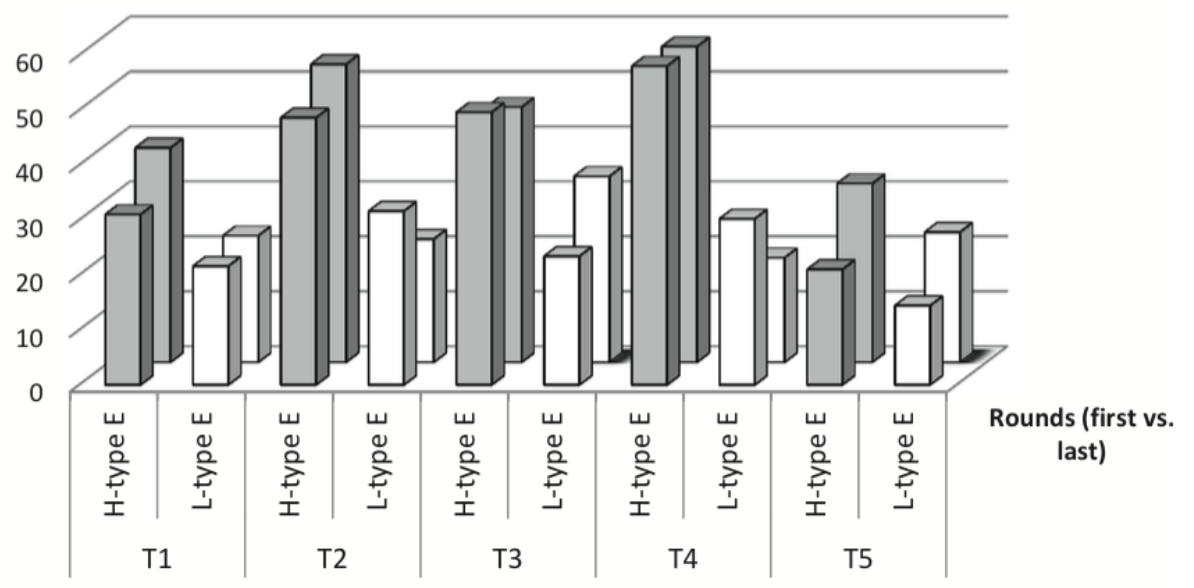

Figure 4: Average one-period payoff by type of player $\mathrm{E}$ and over time For each type of player and for each treatment, we report the average one-period period during the first rounds ( 1 to 5 ) and the last rounds (6 to 10)

\begin{tabular}{llc}
\hline & Coefficient & (Std. Err.) \\
\hline Treatment 1 & -4.228 & $(-1.14)$ \\
Treatment 3 & -1.109 & $(-0.30)$ \\
Treatment 4 & -2.203 & $(-0.54)$ \\
Contract accepted by F & $30.48^{* * *}$ & $(11.60)$ \\
Player E & $-60.06^{* * *}$ & $(-13.80)$ \\
Overconfidence & 10.06 & $(1.22)$ \\
Self-confidence & -7.262 & $(-1.16)$ \\
Player E of type H & $29.05^{* * *}$ & $(4.67)$ \\
Player E of type H in treatment 4 & $14.40^{* *}$ & $(1.97)$ \\
Constant & $63.05^{* * *}$ & $(18.09)$ \\
\hline$N$ & & 800 \\
$\rho$ & & 0.0223 \\
$\sigma_{u}$ & & 5.016 \\
$\rho_{e}$ & & 33.23 \\
\hline
\end{tabular}

Table 9: The determinants of players' gains

Treatments 1 to 4 are dummy variables with treatment 2 set as the benchmark (see. Table 3 for a full description of the treatments). 


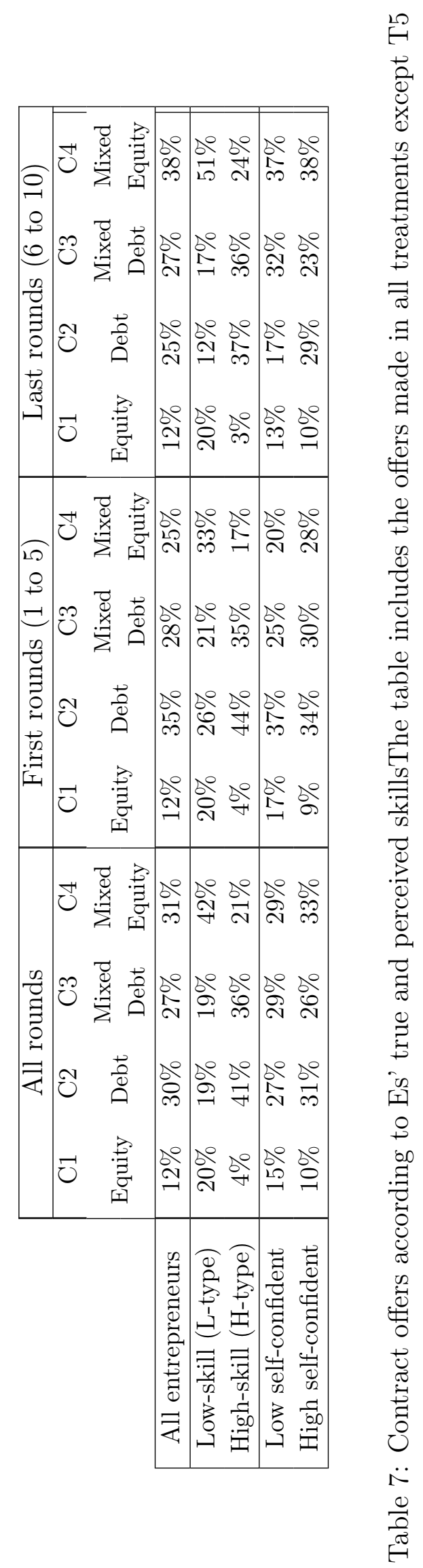




\begin{tabular}{llcc}
\hline & \multicolumn{1}{c}{ C1 (Equity) } & C3 (Mixed Debt) & C4 (Mixed Equity) \\
\hline Overconfidence & $1.019(0.673)$ & $-0.102(0.405)$ & $-0.138(0.409)$ \\
Self-confidence & $-1.682^{* *}(0.587)$ & $-0.347(0.329)$ & $-0.229(0.335)$ \\
Round & $0.261^{* * *}(0.071)$ & $0.232^{* * *}(0.058)$ & $0.342^{* * *}(0.058)$ \\
Reveal_H & $-0.560^{* *}(0.186)$ & $-0.308^{* * *}(0.060)$ & $-0.446^{* * *}(0.072)$ \\
Constant & $-1.277^{* *}(0.412)$ & $-0.607^{*}(0.321)$ & $-1.090^{* *}(0.337)$ \\
\hline $\mathrm{N}$ & 400 & & \\
Log-likelihood & -478.815 & & \\
$\chi^{2}()$. & 106.40 & & \\
Prob $>\chi^{2}()$. & & .000 & \\
\hline
\end{tabular}

Table 8: Multinomial logistic regression for analyzing contract offers with . Standard deviations in parentheses. $(* * *)$ : Significant at the 0.01 level; $(* *)$ : significant at the 0.05 level; $(*)$ significant at the 0.1 level.

The debt contract $\left(C_{2}\right)$ is the base outcome and dependent variables are dummies for self confidence and overconfidence. The reveal_H variable is set to one after a subject learnt his H-type by implementing the "learning through risky choice strategy", otherwise it is equal to zero. Round refers to period 1 to 20. 